\title{
A RESPONSABILIDADE CIVIL DO TERCEIRO QUE INTERFERE DANOSAMENTE NA RELAÇÃO OBRIGACIONAL
}

\author{
Dissertação de Mestrado
}

Orientador: Professor Titular Dr. Fernando Campos Scaff

UNIVERSIDADE DE SÃO PAULO

FACULDADE DE DIREITO

SÃO PAULO - SP

2018 


\section{A RESPONSABILIDADE CIVIL DO TERCEIRO QUE INTERFERE DANOSAMENTE NA RELAÇÃO OBRIGACIONAL}

Dissertação apresentada à Banca Examinadora do Programa de Pós-Graduação em Direito, da Faculdade de Direito da Universidade de São Paulo, como exigência parcial para obtenção do título de Mestre em Direito, na área de concentração Direito Civil, sob a orientação do Professor Titular Dr. Fernando Campos Scaff.

UNIVERSIDADE DE SÃO PAULO

FACULDADE DE DIREITO

SÃO PAULO - SP 
Catalogação da Publicação

Serviço de Biblioteca e Documentação

Faculdade de Direito da Universidade de São Paulo

\author{
Mussi, Lígia Maria Hurga \\ A responsabilidade civil do terceiro que interfere danosamente na \\ relação obrigacional / Lígia Maria Hurga Mussi ; orientador Fernando \\ Campos Scaff -- São Paulo, 2018. \\ $130 \mathrm{p}$. \\ Dissertação (Mestrado - Programa de Pós-Graduação em Direito \\ Civil) - Faculdade de Direito, Universidade de São Paulo, 2018.
}

1. Contratos. 2. Relatividade. 3. Oponibilidade. 4. Terceiro cúmplice. 5. Princípios contratuais. I. Scaff, Fernando Campos, orient. II. Título. 
Nome: Mussi, Lígia Maria Hurga.

Título: A responsabilidade civil do terceiro que interfere danosamente na relação obrigacional

Dissertação apresentada à Faculdade de Direito da Universidade de São Paulo, como exigência parcial para a obtenção do Título de Mestre em Direito, na área de concentração Direito Civil.

Aprovado(a) em:

Banca Examinadora

\begin{tabular}{|l|l|}
\hline Prof.: & Instituição: \\
\hline Julgamento: & Assinatura: \\
\hline Prof.: & Instituição: \\
\hline Julgamento: & Assinatura: \\
\hline Prof.: & Instituição: \\
\hline Julgamento: & Assinatura: \\
\hline Prof.: & Instituição: \\
\hline Julgamento: & Assinatura: \\
\hline Prof.: & Assinatura: \\
\hline & \\
\hline
\end{tabular}




\section{RESUMO}

MUSSI, Lígia Maria Hurga. A responsabilidade civil do terceiro que interfere danosamente na relação obrigacional. 2018. 130 folhas. (Mestrado) - Faculdade de Direito, Universidade de São Paulo, São Paulo, 2018.

A presente dissertação objetiva analisar/reflexionar acerca da responsabilidade civil do terceiro que interfere danosamente na relação obrigacional. O estudo compreendeu pesquisas a respeito do Direito Estrangeiro, relacionadas especificamente aos países Estados Unidos, Inglaterra, Itália, França e Portugal. Nesses ordenamentos, a matéria acerca da responsabilidade civil do terceiro interferente encontra-se um tanto mais desenvolvida, se comparada ao ordenamento brasileiro, e traz importantes contribuições para a contextualização e análise da matéria no Brasil, sem que isso signifique a importação de conceitos alienígenas. Subsequentemente, no âmbito do Direito Brasileiro, busca-se delimitar a figura do terceiro, objeto deste estudo, tendo em vista a pluralidade de significados associados com o vocábulo terceiro. Em seguida, uma reflexão crítica acerca do que se entende por princípios contratuais e cláusulas gerais será apresentada, à luz do que é possível identificar na doutrina e jurisprudência brasileira acerca do tratamento que vem sendo conferido ao tema da responsabilidade civil do terceiro interferente. A reflexão se faz importante, tendo em vista que, por meio dos precedentes existentes acerca do tema, os julgadores pátrios fazem uso, não raro, de critérios imprecisos e vagos, tal como a função social do contrato e/ou a boa-fé objetiva, com a finalidade de justificar a responsabilidade do terceiro interferente, quando, na verdade, o Direito Brasileiro se mostra, muitas vezes, hábil a justificar a regulamentação dessa responsabilidade civil. A partir dessa reflexão, objetivou-se também discutir a interpretação do princípio da relatividade dos efeitos contratuais, segundo o qual não se permite impedir a responsabilização do terceiro por condutas atentatórias à relação obrigacional. Além disso, procurou-se demonstrar que o conceito de oponibilidade, muito bem consolidado no Direito Francês, assim como da relatividade dos efeitos contratuais, fortemente enraizado no Direito Brasileiro, não são complementares, uma vez que atuam em planos diversos. A partir desses pressupostos e reflexões, pretendeu-se expor as contribuições brasileiras, doutrinárias e jurisprudenciais, acerca do tema do presente estudo, além dos fundamentos e requisitos para a configuração da responsabilidade do terceiro interferente. Por fim, antes mesmo de expor a conclusão do presente estudo, procurou-se refletir acerca da natureza jurídica da responsabilidade do terceiro interferente, quer contratual ou extracontratual, além de ponderações acerca dessa responsabilidade, sob a perspectiva da teoria econômica denominada efficient breach of contract, assim como do que se tem posto no Direito Norte-Americano (i.e., Restatement of Torts). Como conclusão, após as análises e reflexões acima mencionadas, objetivou-se estabelecer uma relação entre os elementos associados à responsabilidade civil do terceiro interferente: a relatividade dos efeitos contratuais, a oponibilidade e os limites da responsabilidade civil do terceiro, bem como os parâmetros legais para a regulamentação da conduta danosa de terceiro no âmbito de uma relação obrigacional.

Palavras-chave: contratos, relatividade, oponibilidade, terceiro interferente, terceiro cúmplice, princípios contratuais, responsabilidade civil. 


\begin{abstract}
MUSSI, Lígia Maria Hurga. The civil liability of a third party which harmfully interferes in the obligatory relationship. 2018. 130 sheets. (Master's Degree) - Law School, Universidade de Sao Paulo, Sao Paulo, 2018.

The present paper aims at reflecting upon the civil liability of a third party which harmfully interferes in the obligatory relationship. The present study has encompassed research on Foreign Law specifically related to the United States of America, England, Italy, France and Portugal. In the aforementioned systems, the matter concerning the civil liability of the interfering third party is relatively more evolved if compared to the Brazilian system and brings important contribution to the contextualization and analysis of the matter in Brazil. However, it does not imply the importation of alien concepts. Subsequently, it aims at delimiting the figure of the third party, object of the present study, bearing in mind the plurality of meanings associated with the noun third party. Thereafter, a critical reflection on what is understood by contractual principles and general clauses will be presented in the light of what is possible to be identified in the Brazilian doctrine and jurisprudence law and the treatment which is being given to the theme of civil liability of the interfering third party. The reflection proves to be important, having in mind that by means of the existing precedents to the theme, the national judges not rarely make use of inaccurate and vague criteria, such as the social function of the contract and/or the objective bona fides, with the purpose of justifying the liability of the interfering third party when, as a matter of fact, the Brazilian Law proves to be able to justify the regulation of this civil liability. As from this reflection, the objective of the present study is to discuss the interpretation of the principle of relativity of the contractual effects, according to which it is not permitted to prevent the liability of the third party for offensive conducts as to the obligatory relationship. The present study also aims at demonstrating that the enforceability concept, very well consolidated in the French Law, as well as the concept of relativity of the contractual effects - deeply-rooted in the Brazilian Law -, are not complementary once they act on different plans. From these assumptions and reflections, we have aimed at exposing the Brazilian doctrinaire and case-law contributions on the theme of the present study, besides the fundamentals and requirements for the configuration of the liability of the interfering third party. Finally, even before exposing the conclusion of the present study, there has been an attempt at reflecting on the legal nature of the either contractual or non-contractual liability of the interfering third-party, besides considerations on such liability under the perspective of the economic theory named efficient breach of contract, as well as of what has been stated in the North American Law (e.g., restatement of torts). Finally, after the analysis and reflections aforementioned, the aim has been to establish a relationship among the associated elements to the civil liability of the interfering third-party, namely the relativity of the contractual effects, the enforceability and the limits of the civil liability of the third-party as well as the legal parameters for the regulation of the harmful conduct of the third-party in an obligatory relationship.
\end{abstract}

Keywords: contracts, relativity, enforceability, interfering third party, a third party contractual principles, civil liability. 


\section{Sumário}

Introdução

1. Contribuições do direito estrangeiro: a interferência danosa de terceiro na relação obrigacional: Estados Unidos e Inglaterra (Common law), França, Itália e Portugal ......... 12

1.1. Commom Law - Estados Unidos e Inglaterra: tortius interference of contract ...................... 12

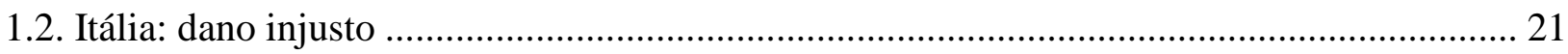

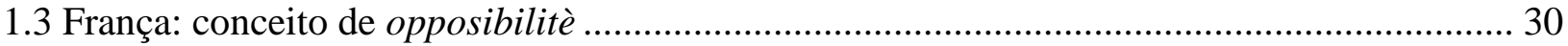

1.4 Portugal: regra geral de responsabilidade civil ................................................................. 37

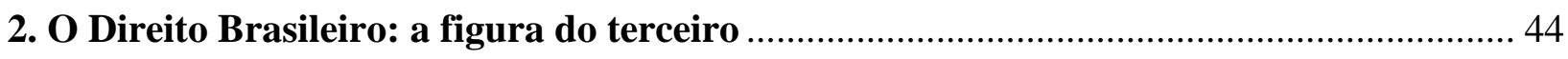

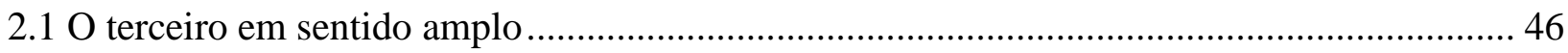

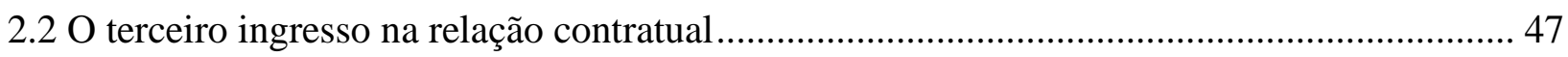

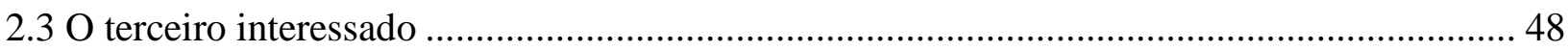

$2.4 \mathrm{O}$ terceiro em conflito com posição jurídica da parte. Oponibilidade. …………………….... 48

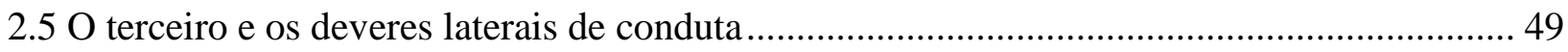

2.6 Conclusão: delimitação. O terceiro que interfere de maneira danosa na relação

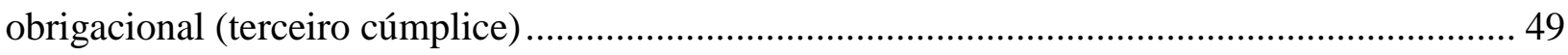

3. O comportamento danoso do terceiro na relação obrigacional no Direito Brasileiro .. 52

3.1 Preliminarmente: aplicação irrestrita de princípios contratuais e fuga para as cláusulas

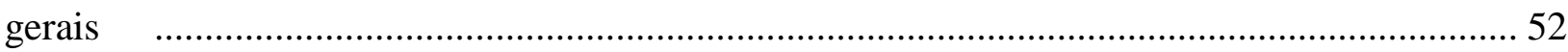

3.2 Efeitos dos contratos perante terceiros: relatividade $v s$. oponibilidade ................................. 65

3.3 As contribuições doutrinárias brasileiras acerca da responsabilização do terceiro por

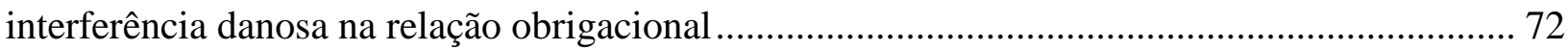

3.4 O cenário brasileiro acerca do tema: análise da jurisprudência............................................. 79

3.4.1 Contrato de Mútuo - Sistema Financeiro de Habitação - Terceiro Cúmplice (REsp

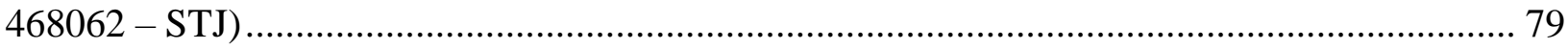

3.4.2 "Caso Zeca Pagodinho" (Ag. Inst. 346.328.4/5 e 346.344.4/8 - TJSP) .............................. 81

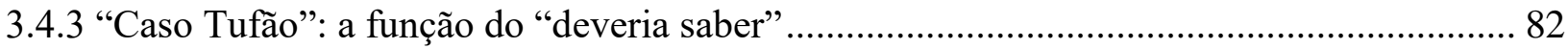

3.5 A responsabilização do terceiro: os seus pressupostos e requisitos......................................... 83

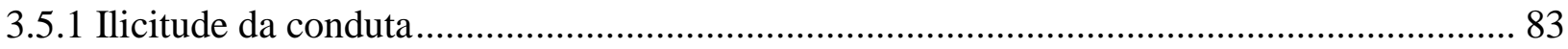

3.5.2 Responsabilidade subjetiva: conhecimento ou possibilidade de conhecimento do contrato pelo terceiro interferente .................................................................................................. 85

3.5.3 Existência de dano. O nexo de causalidade como fator limitador de indenizações.............. 87

4. Questões associadas à responsabilidade do terceiro interferente: reflexões críticas acerca de discussões tangentes ao terceiro interferente e direito estrangeiro ………............8 89

4.1 Responsabilidade civil contratual versus extracontratual ................................................... 90 
4.2 A solidariedade entre o terceiro interferente e o devedor de uma relação obrigacional......... 93

4.3 Restatement of Torts .......................................................................................... 95

4.4 A responsabilização do terceiro que interfere danosamente na relação obrigacional analisada em oposição à teoria do inadimplemento eficiente, "efficient breach" ....................... 97 4.5 Ideias conclusivas: tendências no Direito Brasileiro atual versus esforços de sistematização da responsabilidade civil do terceiro interferente ............................................................ 105

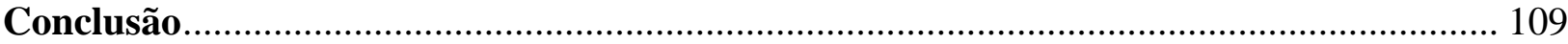

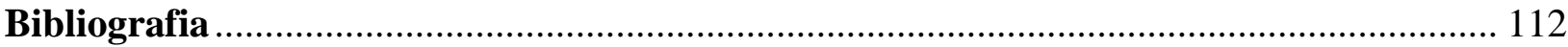




\section{INTRODUÇÃO}

"The problem with the interference tort lies in the complete absence of any principle that will explain to us what judgments to make and why it is that liability sometimes is and sometimes is not imposed".

A discussão acerca da interferência de terceiro na relação obrigacional tem ocupado cada vez mais espaço na doutrina e na jurisprudência brasileiras e tem sido denominada como: "Responsabilidade de terceiro cúmplice da violação de uma obrigação contratual", "Responsabilidade delitual de terceiro em relação a um contratante e de um contratante a respeito de terceiros" ou "A tutela aquiliana do credor contra terceiros".

A hipótese que nos preocupa é a da intervenção do terceiro, inteiramente estranho à relação obrigacional, prejudicando os direitos do credor. Esse terceiro pode, ainda, intervir na relação obrigacional sem a menor cooperação do devedor, impedindo o adimplemento da obrigação, ou que o credor possa auferir as vantagens desse adimplemento, ou pode nela intervir, com a cooperação ou coparticipação do devedor. A presente dissertação diz respeito à responsabilidade do terceiro que instiga o devedor a inadimplir uma determinada relação obrigacional.

A afirmação de que os contratos são elaborados para serem respeitados não causa perplexidade ou estranheza a ninguém. A questão é a possibilidade de reprimenda não só àquele que descumpre o acordo de vontades como àquele que instiga o inadimplemento contratual. A ideia de responsabilização de um terceiro pelo rompimento de um contrato do qual não é parte pode causar surpresa e questionamentos fundamentados, afinal, por não ter participado do pacto, as normas que o regem não poderiam ser opostas em face desse agente. Como, então, imputar a ele responsabilidade pelo desfazimento de um contrato do qual não participou? Segundo quais critérios?

\footnotetext{
${ }^{1}$ DOBBS, Dan D. Tortious interference with contractual relationships. Arkansas Law Review, Fayetteville, v. 34, p. 335-345, 1980.
} 
A resposta para a doutrina chamada pela common law de tortious interference é relativa e aparentemente simples: uma vez que os contratos são elaborados para serem respeitados, ações que os desvirtuem ou os encaminhem para o desenlace devem ser rechaçadas. Podem ser responsabilizados não somente as partes contratualmente vinculadas, como aqueles que, de alguma forma, contribuam para a sua distorção. A linha de conduta contratual passaria a ser oposta a pessoas que nem sequer firmaram o acordo; tudo para que fosse resguardada a expectativa contratual.

Para melhor ilustrar e até mesmo para delimitar o objeto deste estudo, sobretudo pela infinidade de situações, que envolvem terceiros, imaginemos que, almejando expandir seu público consumidor, o dono de um desconhecido posto de combustível deseje exibir a bandeira de renomada empresa do ramo. Para tanto, contrata a futura parceira e juntos optam por firmar um contrato no qual o empresário se compromete a, além de pagar uma determinada quantia mensal, adquirir gasolina e álcool apenas e tão somente da empresa parceira. Essa condição, inclusive, é imprescindível para que haja a manutenção dos padrões de qualidade da companhia, cujo símbolo é exibido. Em um determinado momento, outra fornecedora passa a oferecer preços mais vantajosos ao proprietário do posto, que decide aceitar a proposta. Ao comprar combustível de um concorrente, o dono do posto afronta a cláusula de exclusividade que mantinha. Diante desse descumprimento voluntário, mas instigado, a teoria do terceiro cúmplice aponta que tanto o dono do posto quanto o concorrente poderiam ser responsabilizados pelos danos advindos da quebra do contrato pré-existente.

Em caso semelhante, esse foi o entendimento da $1^{\mathrm{a}}$ Câmara Reservada de Direito Empresarial do Tribunal de Justiça de São Paulo, que considerou legítimo que aquele que estimulou o descumprimento da obrigação contratual figurasse no polo passivo da ação de abstenção da venda e da distribuição de combustíveis. O mesmo Tribunal de Justiça também já entendeu pela possibilidade de condenar o terceiro cúmplice pelos danos materiais e morais sofridos pela parte prejudicada ${ }^{2}$.

\footnotetext{
${ }^{2}$ BRASIL. Tribunal de Justiça de São Paulo. Apelação nº. 0192396-15.2011.8.26.0100. Relator: Desembargador Enio Santarelli Zuliani. São Paulo 11 de dezembro de 2012; Agravo de Instrumento $\mathrm{n}^{\circ}$. 008484007.2004.8.26.0000. Relator: Desembargador Roberto Mortari. São Paulo, 31 de março de 2004; Agravo de
} 
A responsabilização do terceiro estaria fincada, então, em conduta visivelmente maliciosa, caracterizada pelo auxílio ao descumprimento de pacto do qual não é parte, para nova contratação cujo conteúdo é incompatível com o pré-existente. Essa articulação entre o terceiro que interfere em relação contratual alheia para se valer de algum benefício e a parte diretamente responsável pelo rompimento contratual seria condenável, pois, embora o terceiro desconhecesse as condições do contrato firmado entre o dono do posto e a empresa de combustível, por atuar na área, era de se esperar que soubesse da existência de vínculo de exclusividade. Não fosse a inoportuna proposta incitando o rompimento do vínculo contratual, o pacto anteriormente firmado permaneceria estável e a expectativa e a confiança intrínsecas à relação anterior permaneceriam inabaladas.

A mesmíssima lógica pode ser constatada quando, vendo o crescimento da audiência de determinado talk show, por se tratar de formato facilmente transportável para outro canal, a emissora concorrente decide oferecer para todos seus integrantes contratos mais longos e mais bem remunerados, incitando o elenco do programa a aceitar a proposta. Vê-se que a atuação da rival é fundamental para que haja a migração do casting. O proveito da proposta para aquele que a faz e para os que a aceitam salta aos olhos, assim como o prejuízo daquele que vê sua atração se esfacelar. Também nesse exemplo, caso aplicada a doutrina do terceiro cúmplice, poderia haver responsabilização daqueles que, de alguma forma, contribuíram para o término do contrato.

É possível mencionar famosos episódios tratados pela jurisprudência pátria e que serão analisados ao longo deste estudo. Um deles é o caso do Zeca Pagodinho e duas cervejarias; outro é o do ator Murilo Benício quando atuava em novela de grande repercussão.

A doutrina do terceiro cúmplice, embora não seja nova, carece de melhor sistematização pela doutrina brasileira e pelos Tribunais pátrios. Apesar de relativamente aceita e atualmente fundada no princípio da função social do contrato (artigo 421 do Código Civil), o seu acolhimento remanesce incerto e imprevisível, sobretudo por sua aplicação

Instrumento $n^{\circ}$. 9007813-47.2008.8.26.0000. Relator: Desembargador Renato Rangel Desinano. São Paulo, 23 de outubro de 2008. 
contrariar alguns dogmas da teoria contratual, fortemente enraizados, tal como a eficácia subjetiva do contrato e o princípio da relatividade dos efeitos do contrato.

Não se pretende descredenciar, neste estudo, a relevância do princípio da função social do contrato ou de qualquer outro princípio contratual. Busca-se a análise fundamentada e positivada dos requisitos para a responsabilização do terceiro interferente, afastando-se a aplicação exacerbada pela doutrina e pela jurisprudência dos princípios contratuais acima referidos.

A análise detida e detalhada acerca da responsabilidade do terceiro cúmplice abrange, no âmbito civil, reflexões importantes acerca do artigo 608 do Código Civil (i.e., previsão de aliciamento de prestadores de serviços), cuja correspondência se encontrava no artigo 1.235 do Código Civil de 1916 e, de certa forma, no Statute of Laboreur (Inglaterra).

Além disso, temas como oponibilidade, relevância do conhecimento da obrigação da interferência, nexo de causalidade, entre outros, são vitais para a construção e para a conclusão deste estudo.

De maneira a sistematizar as respostas às questões associadas à responsabilização do terceiro interferente na relação obrigacional, iniciaremos pelas contribuições do Direito Estrangeiro no Capítulo 1. Não há qualquer pretensão de exaurir o tema nos ordenamentos escolhidos (i.e., Estados Unidos da América, Inglaterra, França, Itália e Portugal), tampouco qualquer intenção de se propor uma mera importação de conceitos. É incontroverso que esses ordenamentos forasteiros trazem importantes subsídios de mais de um século acerca dos terceiros, objeto deste estudo, e obrigações: (i) o pionerismo da Inglaterra e dos Estados Unidos da América no tratamento da tortius interference of contract; (ii) os conceitos de relatividade e de oponibilidade (relativitè e opposabilitè), cuidadosamente maturados e consolidados na França; (iii) o danno ingiusto do Direito Italiano, que delimita de maneira ampla a responsabilização de terceiros e (iv) a teoria e os respectivos fundamentos teóricos do abuso de direito presentes no ordenamento português 
No Capítulo 2, ingressaremos no Direito Brasileiro propriamente, iniciando pela apresentação das figuras do terceiro presentes no ordenamento pátrio. O objetivo, com essa incursão introdutória no Direito Brasileiro, é delimitar a figura do terceiro que interfere danosamente na relação obrigacional, de maneira a evitar generalizações e consequências equivocadas ao fim deste estudo.

No Capítulo 3, será desenvolvida uma análise pormenorizada da doutrina e da jurisprudência brasileiras, além da reflexão crítica acerca da relatividade dos efeitos do contrato e do conceito de oponibilidade e a organização sistematizada dos requerimentos legais para a configuração da responsabilidade do terceiro interferente na relação obrigacional, que não única e exclusivamente por meio dos princípios contratuais.

No Capítulo 4, serão examinadas a natureza dessa responsabilidade de terceiro interferente, as consequências jurídicas do comportamento danoso do terceiro e, de maneira não exaustiva, a relação entre a responsabilidade do terceiro e a teoria do efficient breach, existente no âmbito do campo da law e economics.

$\mathrm{Na}$ Conclusão, serão recapitulados os fundamentos, as bases e os requerimentos da responsabilização do terceiro interferente, cujo objetivo é contribuir para a melhor sistematização e tratamento dessa responsabilidade no ordenamento brasileiro. 


\section{CONCLUSÃO}

A questão da interferência do terceiro em uma relação obrigacional, apesar de difundida no Direito Brasileiro, encontra-se, ainda, carente de uma melhor sistematização. Os dogmas fortemente enraizados relacionados com temas do direito privado e com a teoria contratual, especificamente a relatividade dos efeitos contratuais e a eficácia subjetiva do contrato, por exemplo, permitem, muitas vezes, a supervalorização de justificativas fundamentadas em princípios contratuais e em cláusulas gerais, retardando e, até mesmo, impedindo, a adequada estruturação e a metodização da responsabilidade civil do terceiro interferente.

A regulamentação da referida responsabilidade civil, ainda que não integralmente expressa no conjunto de normas e de dispositivos legais existentes ${ }^{178}$, deve enfrentar, obrigatoriamente, temas associados com a teoria geral do direito privado (i.e., a relatividade dos efeitos contratuais, os limites da responsabilidade civil do terceiro interferente e a oponibilidade), de modo a evitar confusões e a permitir a adequada sistematização da matéria.

A despeito do pioneirismo e do protagonismo do Direito Estrangeiro no tocante ao tema deste estudo, inclusive no âmbito da jurisprudência alienígena, é perceptível, no Direito Brasileiro, a tendência de os tribunais se valerem de conceitos vagos, abertos e imprecisos, tal como o da função social do contrato, o da boa-fé objetiva, dentre outros, para justificar a responsabilidade civil do terceiro interferente, como no caso emblemático e de alta popularidade envolvendo o cantor Zeca Pagodinho.

Ao mencionar o Direito Estrangeiro no parágrafo acima e ao longo deste estudo, não se pretendeu inferir qualquer importação de conceitos e/ou de soluções de ordem prática, mas, nos termos do que foi exposto anteriormente, sobretudo no Capítulo primeiro e no Capítulo quarto, parece razoável afirmar que (i) o Direito Estrangeiro possui alguma

${ }^{178}$ Como demonstrado ao longo deste trabalho, a interferência do terceiro nos contratos de prestação de serviços está expressamente disposta no artigo 608 do Código Civil. 
vantagem sob a perspectiva de maturidade, se comparado com o Direito Brasileiro, associada com os conceitos de relatividade dos efeitos contratuais e de oponibilidade, sem os quais a sistematização da responsabilidade civil do terceiro resta prejudicada e (ii) a sistematização, ainda que não exaustiva da matéria, como a existente no Restatement of Torts, permite a reflexão sobre a dimensão de variáveis existentes envolvendo o terceiro interferente, além da organização de parâmetros objetivos, de maneira a reduzir a margem de incerteza acerca do tratamento da responsabilidade civil do terceiro interferente, pela doutrina e/ou pela jurisprudência.

Não se pretendeu diminuir ou relegar à insignificância os princípios contratuais e as cláusulas gerais existentes no Direito Brasileiro, tampouco no que se refere à autonomia da vontade, mas propor uma reflexão acerca da capacidade de esses princípios contratuais e de essas cláusulas gerais justificarem e solucionarem toda e qualquer situação envolvendo o terceiro interferente de uma relação privada.

A relatividade dos efeitos contratuais não impede a responsabilização de terceiros alheios ao pacto contratual, já que opera entre as partes contratantes, em plano diverso da oponibilidade, não figurando, portanto, como óbice à responsabilização.

O artigo 186 do Código Civil dispõe sobre o ato ilícito, o qual consiste na violação do direito de outrem e figura como verdadeiro fundamento para a responsabilidade civil de terceiro, conjuntamente com os artigos 187, 927 e 942 do Código Civil. É imprescindível, para a configuração da responsabilidade civil, a existência de um ato ilícito, do dano e do nexo de causalidade entre o ato ilícito e o dano. É imprescindível também que o terceiro interferente tenha conhecimento da, ou a possibilidade de conhecer a, relação obrigacional que pretende prejudicar, sendo, portanto, o dolo elemento essencial para a configuração dessa responsabilidade civil.

A responsabilidade civil será solidária entre o terceiro interferente e o devedor inadimplente, parte da relação obrigacional, tendo por fundamento a responsabilidade contratual e extracontratual, respectivamente. 
Por meio desta dissertação, procuramos apresentar as pesquisas mais atualizadas acerca do tema, além de uma reflexão importante sobre os pressupostos e os requisitos para a configuração da responsabilidade civil do terceiro interferente, buscando contribuir para uma adequada sistematização da matéria. 


\section{BIBLIOGRAFIA}

AGUIAR JÚNIOR., Ruy Rosado de. O Poder Judiciário e a concretização das cláusulas gerais: limites e responsabilidade. Revista da Faculdade de Direito da UFRGS, v18, 2000, p. 221-228.

ALPA, Guido. La responsabilité civile en Italie: problèmes et perspectives. Revue Internationale de Droit Comparé, Paris, v. 38, n. 4, oct./dec. 1986.

ALPA, Guido; FERRANDO, Gilda. La lesione del diritto di credito da parte di terzi. La Nuova Giurisprudenza Civile Comentata, anno 1, parte prima, 1985.

ANTUNES VARELA, João de Matos. Das obrigações em geral. 10. ed. Coimbra: Almedina, 2012.

BANAKAS, Statis K. Transformazioni della responsabilità extracontratuale. Rivista di Diritto Civile, Padova, v. 44, n. 1, genn./febb. 1998.

BANDEIRA, Paula Greco. Fundamentos da responsabilidade civil do terceiro cúmplice. RTDC: Revista Trimestral de Direito Civil, Rio de Janeiro, v. 8, n. 30, abr./jun. 2007.

BARBERO, Domenico. Responsabilitá aquiliana per lesione di rapport personale. Il Foro Padano, v. 6, 1951.

BDINE JÚNIOR, Hamid Charaf. Efeitos do negócio jurídico nulo. São Paulo: Saraiva, 2010 (Coleção Professor Agostinho Alvim).

BEATER, Axel. Generalklauseln und Fallgrupen. Erwiderung auf Ralph Weber, AcP 1992. Archiv für die Civilistische Praxis, n. 194, 1º caderno, Tübingen: Mohr, 1994.

BENACCHIO, Marcelo. Responsabilidade civil contratual. São Paulo: Saraiva, 2011. 
BESSONE, Mario. Lesione del credito, l'induzione a non adempiere, la tutela aquiliana dei diritti personali di godimento negli orientamenti di uma giurisprudenza evoluta. Rivista del Notariato Rassegna di Diritto e Pratica Notarile, v. 36, 1982.

BETTI, Emilio. Sui limiti giuridici della responsabilità aquiliana. Nuova Rivista di Diritto Commerciale, Diritto dell'Economia, Diritto Sociale, v. 4, pt. 1, 1951.

BETTI, Emilio. Teoria geral do negócio jurídico. T.1. Tradução de Fernando de Miranda. Coimbra: Coimbra, 1969.

BEVILAQUA, Clovis. Código Civil dos Estados Unidos do Brasil.V.1. Rio de Janeiro: Ed. Rio, 1976.

BEVILAQUA, Clovis. Direito das obrigações. 8 ed. EdiçãoRevista e atualizada por Achilles Bevilaqua. Rio de Janeiro: Francisco Alves, 1954.

BIANCA, Cesare Massimo. Diritto Civile, III, Il contratto. 2 ed. Milão: Giuffrè, 2000.

BIGIAVI, Luigi. L'associazione Calcio Torino e il disastro di Superga. Giur. it, 1951.

BOULOS, Daniel Martins. Abuso de direito no novo Código Civil. São Paulo: Método, 2006.

BRASIL. Superior Tribunal de Justiça. Recurso Especial nº 1.316.149-SP, $3^{\mathrm{a}}$ Turma, Relator: Ministro Paulo de Tarso Sanseverino. Brasília, 03 de junho de 2004.

BRASIL. Superior Tribunal de Justiça. Recurso Especial $n^{\circ}$. 1.203.153, Relator: Ministro Paulo de Tarso Sanseverino. Brasília 3 de junho de 2014.

BRASIL. Superior Tribunal de Justiça. Recurso Especial nº. 721.231, 4a Turma, Relator: Ministro João Otávio de Noronha. Brasília 8 de abril de 2008. 
BRASIL. Superior Tribunal de Justiça. Recurso Especial nº. 1.102.437, $3^{\mathrm{a}}$ Turma, Relator: Ministra Nancy Andrighi. Brasília, 07 de outubro de 2010.

BRASIL. Superior Tribunal de Justiça. Recurso Especial $n^{\circ}$. 187.940, 4a Turma, Relator: Ministro Ruy Rosado de Aguiar. Brasília, 18 de fevereiro de 1999.

BRASIL. Superior Tribunal de Justiça. Recurso Especial nº. 936.589, $3^{\text {a }}$ Turma, Relator: Ministro Sidnei Beneti. Brasília, 08 de fevereiro de 2011.

BRASIL. Superior Tribunal de Justiça. Recurso Especial $n^{\circ}$. 468.062, Relator: Ministro Humberto Martins. Brasília, 11 de novembro de 2008.

BRASIL. Tribunal de Justiça do Estado de São Paulo. Apelação no . 643404-00/4, 10 Câmara do Segundo Tribunal de Alçada Civil, Relator: Juiz Gomes Varejão. São Paulo, 06 de novembro de 2002.

BRASIL. Tribunal de Justiça do Estado do Rio Grande do Sul. Apelação no. 70047718473, 12a Câmara Cível, Relator: Desembargador Umberto Guaspari Sudbrack. Porto Alegre, 27 de fevereiro de 2014.

BRASIL. Tribunal de Justiça do Estado de São Paulo. Agravos de Instrumento no .s 346.3284/5-00 e 346.344.4/8-00, $7^{\text {a }}$ Câmara de Direito Privado, Relator: Desembargador Roberto Mortari. Brasília, 31 de março de 2004.

BUSNELLI, Francesco Donato. La lesione Del credito da parte di terzi. Milano-Dott: Giuffrè, 1964.

BUSNELLI, Francesco Donato. Un clamoroso 'revirement' della Cassazione dalla 'questione di Superga' al 'caso Meroni. Foro Italiano. v. 1, 1971. 
BUSNELLI, Francesco Donato; PATTI, Salvatore. Danno e responsabilità civile. 3 ed. Torino: G. Giappichelli, 2013.

CA Paris, 2 de outubro de 1992, D. 1995, somm. 83.

CALASTRENG, Simone. La relativitè des conventions: étude de l'article 1165 du Code Civil. Paris: Recueil Sirey, 1939.

CARDOSO, Patrícia. Oponibilidade dos efeitos dos contratos: determinante na responsabilidade civil do terceiro que coopera com o devedor na violação do pacto contratual. Revista Trimestral de Direito Civil, Rio de Janeiro, ano 5, v. 20, out./dez. 2004.

CARPENTER, Charles E. Interference with contract relations. Harvard Law Review, n. 41, 1927-1928.

FRANCE. Cour de Cassation Commerciale, arrêt du 13 de mars 1979. Bull. Civ. IV, n. 100.

CASSETTARI, Christiano. Elementos de direito civil. 3 ed. São Paulo: Saraiva, 2015.

CAVALIERI FILHO, Sérgio. Programa de responsabilidade civil. 11. ed. São Paulo: Atlas, 2014.

CORDEIRO, António Menezes. Direito das obrigações. V. I. Lisboa: 1980.

CORREIA, Antonio de Arruda Ferrer. Da responsabilidade do terceiro que coopera com o devedor na violação de um pacto de preferência. Estudos de direito civil, comercial e criminal. 2 ed. Coimbra: Almedina, 1985.

CORSARIO, Luigi. Colpa e responsabilità civile: l'evoluzione del sistema italiano. Rassegna di Diritto Civile, Napoli, n. 2, 2000. 
COSTA, Mário Júlio de Almeida. Direito das obrigações. 9 ed. Coimbra: Almedina, 2001.

COUTO E SILVA, Clóvis. O direito civil brasileiro em perspectiva histórica e visão do futuro. Revista Ajuris, Porto Alegre, n. 40.

DE CUPIS, Adriano. Il damno: teoria generale della responsabilità civile. Milano: Giuffrè, 1979.

DEMOGUE, René. Traité des obligations en general. V. 7. Paris: Rousseau, 1923.

DI MARTINO, Patrizia. La responsabilità del terzo 'complice' nell'inadempimento contrattuale. Rivista Trimestrale di Diritto e Procedura Civile, Milano, ano 29, n. 4, 1975.

DÍEZ-PICAZO, Luiz; GULLÓN, Antonio. Sistema de derecho civil. V. II, 4. ed. Madrid: Tecnos, 1983.

DINIZ, Davi Monteiro. Aliciamento no contrato de prestação de serviços: responsabilidade de terceiro por interferência ilícita em direito pessoal. Revista Síntese de Direito Civil e Processual Civil, ano V, v. 27, jan./fev. 2004.

DOBBS, Dan D. Tortious interference with contractual relationships. Arkansas Law Review, Fayetteville, v. 34, p. 335-345, 1980.

DRAETTA, Ugo. The Pennzoil case and the binding effect of intent in the international trade practice. Revue de Droit des Affaires Internacionales, n. 2, p. 155, 1988.

DUCLOS, José. L’opposabilité: essai d’une théorie générale. Paris: LGDJ, 1984.

DUVAL, Hermano. Concorrência desleal. São Paulo: Saraiva, 1976. 
FERNANDES, Wanderley. O processo de formação do contrato. In: (Coord.).

Fundamentos e princípios dos contratos empresariais. São Paulo: Saraiva, 2007. (Série GVLaw).

FERRANDO, Gilda. La lesione del Diritto di Credito da Parte di Terzi. Nuova Giur. Comm., v. II, 1985.

FIGUEIREDO, Helena Lanna. Responsabilidade Civil do terceiro que interfere na relação contratual. Belo Horizonte: Del Rey, 2009.

FORGIONI, Paula Andrea. Interpretação dos negócios empresariais. In: FERNANDES, Wanderley (coord.). Fundamentos e princípios dos contratos empresariais. São Paulo: Saraiva, 2007. (Série GVLaw).

FRANCE. Cour de Cassation Commerciale, 3éme Chambre Civile, arrêt du9 juillet 1975, Gaz. Pal. 1975, n. 2.

FRANCE. Cour de Cassation Commerciale. 1ére Chambre Civile, arrêt du 27 octobre 1992, Dalloz (Jur. Gén.) 1992.

FRANCE. Cour de Cassation. 1ére Chambre Civile, ârret du 10 avril 1982. Bull civ. I, n. 139.

FRANZONI, Massimo. La rilevanza del contratto verso i terzi. In: D’ANGELO, Andrea e ROPPO, Vincenzo (a cura di). Annuario del contratto 2013. Torino: G. Giappicheli, 2014.

GAMBARO, Antonio. Gli effetti del contratto rispetto ai terzi. In: VACCA, Letícia (a cura di). Gli effetti del contratto nei confronti dei terzi nella prospettiva storico-comparatistica. Atti del $4^{\circ}$ Congresso Intgernazionale Aristec (Roma, 13-16 sett. 1999). Torino: Giappichelli, 2001.

GERMAN. Civil Code. BGB. Disponível em <www.gesetze-im-internet.de/englishch_bgb/>. 
GHESTIN, Jacques. Introdution. In: FONTAINE, Marcel; GHESTIN, Jacques. Les effets du contrat à l'egard des tiers. Paris: LGDJ, 1992.

GODOY, Claudio Luiz Bueno de. A função social do contrato: os novos princípios contratuais. 4. ed. São Paulo: Saraiva, 2012.

GOMES, Orlando. Responsabilidade civil. Edvaldo Brito (Coord.). Rio de Janeiro: Forense, 2011.

GOMES, Orlando. Contratos. 26 ed. Rio de Janeiro: Forense, 2007.

GONÇALVES, Carlos Roberto. Direito civil brasileiro: contratos e atos unilaterais. V. 3, 11. ed. São Paulo: Saraiva, 2014.

GONDIM, Glenda Gonçalves; KENICKE, Paulo Henrique Gallotti; BERTASSONI, Thaís Braga. A causa, os planos do negócio jurídico e a função social: análise a partir da teoria do terceiro cúmplice. In: TEPEDINO, Gustavo; FACHIN, Luiz Edson (Orgs.). Pensamento crítico do direito civil brasileiro. Curitiba: Juruá, 2011.

GOUTAL, Jean-Louis. Essai sur le príncipe de l'effet relatif do contrat. Paris: LGDJ, 1981.

GOUTAL, Jean-Louis. Le Principle de l'Effet relatif Du Contrat. T. CLXXI. Paris: Librairie Générale de Droit et de Jurisprudence, 1981.

GRECO, Paolo. Se un'associazione calcistica ha diritto a risarcimento del danno aquiliano per la perdita della sua squadra avvenuta durante un trasporto aereo. Rivista del Diritto Commerciale e del Diritto Generale delle Obbligazioni, Milano, anno 49, pt. 1.

GUARNIERI. Diritti reali e diritti di credito: valore attuale di una distinzione. Padova: Cedam, 1979. 
GUELFUCCI-THIBIERGI, Catherine. De l'elargissement de la notion de partie au contrat à l'elargissement de la portée du príncipe de l'effet relatif. Revue Trimestrielle de Droit Civil, Paris, v. 93, n. 2, avr./juin. 1994.

HEDEMANN, Justus Wilhelm. Die Flucht in die Generalklauseln: Eine Gefahr für Recht und Staat. Tübingen: Mohr, 1933.

HIRONAKA, Giselda Maria Fernandes Novaes. A função social do contrato. Revista de Direito Civil, imobiliário, agrário e empresarial, São Paulo, ano 12, jul./set. 1998.

HUGUENEY, Pierre. Responsabilité civile du tiers complice de la violation d'une obligation contractuelle. Paris: A. Rousseau, 1910.

ITALIA. Corte d'Appelo di Torino. Sentenza 27 gennaio 1969. Romero c. s.p.a. Torino Calcio. Foro italiano, 1969, I.

ITALIA. Corte d'Appelo di Torino. Sentenza 28 gennaio 1952, Pres. De Matteis P., Rel. Caprioglio, Est. Merlo, Ass. Calcio Torino c. Soc. A.l.i. Flotte riunite. Foro Italiano, volume LXXV, 1952.

ITALIA. Corte di Cassazione, Sez. III, Pres. Valenzi, Est. Mastrapasqua, P. M. Berri, Associazione Calcio Torino c. Soc. A.L.I. Flotte Riunite. Giustizia Civile, anno III, 7-8, luglio-agosto, 1953.

ITALIA. Corte di Cassazione. Sentenza 26 gennaio 1971. S.p.a. Torino Calcio c. Romero. Foro italiano, 1971, I.

ITALIA. CORTE DI CASSAZIONE, sezione III, sentenza 4 luglio 1953, n. 2085, Pres. Valenza. In: Lex Aquilia Giurisprudenza. 
ITALIA. CORTE DI CASSAZIONE, sezione unite, senteza 26 gennaio 1971, n. 174, Pres. Stella Richter. In: Lex Aquilia Giurisprudenza.

IZORCHE, Marie-Laure. Les effets des conventions à l'egard des tiers: l'éxperience française. In: VACCA, Letizia (Dir.). Gli effetti del contratto nei confronti dei terzi nella prospettiva storico-comparatistica. Torino: Giappichelli, 2001.

JORGE, Fernando Pessoa. Lições de direito das obrigações. Lisboa: AAFDL, 1975.

JÓZON, Mónika. Non-contractual liability arising out of damage caused to another. In: ANTONIOLLI, Luisa; FIORENTINI, Francesca (Eds.). A factual assessment of the draft common frame of reference. Munich: Sellier European Law Publishers, 2011.

JUNQUEIRA DE AZEVEDO, Antonio. Diferenças de natureza e efeitos entre o negócio jurídico sob condição suspensiva e o negócio jurídico a termo inicial. A colaboração de terceiro para o inadimplemento de obrigação contratual. A doutrina do terceiro cúmplice. A eficácia externa das obrigações. In: Estudos e Pareceres de Direito Privado, São Paulo, Saraiva, 2004.

JUNQUEIRA DE AZEVEDO, Antonio. Novos estudos e pareceres de direito privado. São Paulo: Saraiva, 2009.

JUNQUEIRA DE AZEVEDO, Antonio. Os princípios do atual direito contratual e a desregulamentação do mercado. Direito de exclusividade nas relações contratuais de fornecimento. Função social do contrato e responsabilidade aquiliana do terceiro que contribui para inadimplemento contratual.In Estudos e Pareceres de Direito Privado, São Paulo, Saraiva, 2004.

JUNQUEIRA DE AZEVEDO, Antônio. Negócio Jurídico: existência, validade e eficácia. 4 ed. . São Paulo: Saraiva, 2002. 
KAMANABROU, Sudabeh. Die Interpretation zivilrechtlicher Generalklauseh. Archiv für die Civilistische Praxis, n. 202, p.662-688, $4^{\circ}$ e $5^{\circ}$ cadernos, Tübingen: Mohr, 2002.

LALOU, Henri. 1382 contre 1165 ou la responsabilité délictuelle des tiers à l'egard d'un contractant et d'un contractant à l'egard des tiers. Paris: Dalloz, 1928 (Chronique, n. 32).

LALOU, Henri. La responsabilité civile: principle élémentaires et applications pratiques. 2 ed. Paris: Dalloz, 1932.

LARENZ, Karl. Base del negocio juridico y cumplimiento de los contratos. Tradução de Carlos Fernandes Rodriguez. Madrid: Revista de Derecho Privado, 1956.

LAURROMET, Christian ; BROS, Sara. Traité de Droit Civil. T.3, 4 ed. Paris: Economica.

LEWIN, Tamar. Pennzoil-Texaco fight raised key questions. The New York Times, New York, 19 Dec. 1987. Disponível em: <http://www.nytimes.com/1987/12/19/business/pennzoiltexaco-fight-raised-key-questions.html?pagewanted=all>. Acesso em: 09 jan. 2018.

LIMA, Alvino. A interferência de terceiros na violação do contrato. Revista dos Tribunais, v. 315, jan. 1962, p. 14-30.

LIMA, Alvino. Da culpa ao risco. São Paulo: Revista dos Tribunais, 1938.

LOPEZ, Teresa Ancona. Comentários ao Código Civil: parte especial, das várias espécies de contratos (arts. 565 a 652). JUNQUEIRA DE AZEVEDO, Antonio (coord.). V. 7. São Paulo: Saraiva, 2009.

LOPEZ, Teresa Ancona. Princípios contratuais. In: FERNANDES, Wanderley (Coord.). Fundamentos e princípios dos contratos empresariais. São Paulo: Saraiva, 2007. (Série GVLaw). 
LORDI, Luigi. Contratto a danno di terzi e danno recato da um terzo a un contratante, Rivista del Diritto Commerciale, v. II, 1937.

LOUREIRO, Luiz Guilherme. Curso completo de direito civil. 3 ed. São Paulo: Método, 2010. Lumley v. Gye, [1853] All ER Rep 208, High Court (QBD), e Tony Weir, A Casebook on Tort, 9a edição, Londres, Sweet \& Maxwell, 2002.

MARCHESSAUX, Isabelle. L'opposabilité du contrat aux tiers. In: FONTAINE, Marcel; GHESTIN, Jacques. Les effets du contrat à l'egard des tiers. Paris: LGDJ, 1992.

MARINO, Francisco Paulo de Crescenzo. Contratos coligados no direito brasileiro. São Paulo: Saraiva, 2009.

MARTINO, Patrizia Di. La responsabilità del terzo complice nell'inadempimento contrattuale. RTDPC, Ano XXIX, 1975.

MARTINS, Camila Rezende. O princípio da relatividade dos contratos e responsabilidade do terceiro que contribui para o inadimplemento contratual. Dissertação de Mestrado Faculdade de Direito da Universidade de São Paulo, São Paulo, 2011.

MARTINS, Fábio Floriano Melo. A interferência lesiva de terceiro na relação obrigacional. Tese de Doutorado - Faculdade de Direito da Univesidade de São Paulo, São Paulo, 2015.

MARTINS, Fábio Floriano Melo. A interferência lesiva de terceiro na relação obrigacional. São Paulo: Almedina, 2017.

MARTINS, José Eduardo Figueiredo de Andrade. Duty to mitigate the loss no direito civil brasileiro. Dissertação de Mestrado - Faculdade de Direito da Universidade de São Paulo, São Paulo, 2014. 
MARTINS-COSTA, Judith. A boa fé no Direito Privado. Revista dos Tribunais: São Paulo, 1999.

MARTINS-COSTA, Judith. Reflexões sobre o princípio da função social do contrato. Revista Direito GV, São Paulo, v. 1, n. 1, maio 2005.

MARTINS-COSTA, Judith. Zeca Pagodinho, a razão cínica e o novo código civil brasileiro. Migalhas. Disponível em: <http://www.migalhas.com.br/dePeso/16,MI4218,101048Zeca+Pagodinho+a+razao+cinica+e+o+novo+Codigo+Civil+Brasileiro>. Acesso em: 13 dez. 2017.

MAZEAUD, Henri. Responsabilité délictuelle et responsabilité contractuelle. Revue Trimestrielle de Droit Civil, Paris, v. 28, 1929.

MC CHESNEY, Fred S. Tortious interference with contract versus "efficient" breach: Theory and Empirical evidence. The Journal of Legal Studies, v. XXVIII, Jan. 1999, University of Chicago.

MENEZES CORDEIRO, Antonio. Tratado de direito civil português: direito das obrigações. V. II, t. I. Coimbra: Almedina, 2009.

MENEZES CORDEIRO, António. Direitos das obrigações. V. I. Lisboa, 1980.

MENKE, Fabiano. A interpretação das cláusulas gerais: a subsunção e a concreção dos conceitos. Revista do Direito do Consumidor, v. 50, p. 9, Abr. 2004.

MIGUELETTO, D. C. R. Organizações em rede. Dissertação de mestrado em administração pública - Escola Brasileira de Administração Pública, Fundação Getúlio Vargas, Rio de Janeiro, 2001. 
MIRANDA, Francisco Cavalcanti Pontes de. Tratado de Direito Privado: parte especial. V. 26, T. XXXIII. Atualizado por Alcides Tomasetti Jr. e Rafael Domingos Faiardo Vanzella. São Paulo: Revista dos Tribunais, 2012.

MIRANDA, Francisco Cavalcanti Pontes de. Tratado de direito privado: direito das obrigações - consequências do inadimplemento, exceções do contrato não adimplido. T. XXVI. Atualizado por Ruy Rosado de Aguiar Júnior e Nelson Nery Júnior. São Paulo: Revista dos Tribunais, 2012.

MONATERI, Pier Giuseppe. Responsabilità extracontrattuale fattispecie. Rivista di Diritto Civile, Padova, v. 40, n. 6, nov./dic. 1994.

MONCADA, Luís Cabral de. Lições de direito civil. 4 ed. Coimbra: Almedina, 1995.

MOREIRA, Guilherme Alvez. Instituições do direito civil português. V. II. Coimbra: 1911.

MORSELLO, Marco Fábio. Contratos existenciais e de lucro: análise sob a ótica dos princípios contratuais contemporâneos. In: MARTINS, Fernando Rodrigues; NANNI, Giovanni Ettore; LOTUFO, Renan (Coords.). Temas relevantes do direito civil contemporâneo. São Paulo: Atlas, 2012.

MOSCATI, Enrico. Il contratto e la responsabilità dei terzi. In: VACCA, Letizia (Dir.). Gli effetti del contratto nei confronti dei terzi nella prospettiva storico-comparatistica. Torino: Giappichelli, 2001.

MOZZATO, Anelise Rebelato; GOLlO, Silvana Saionara. Redes de cooperação como vantagem competitiva: estudo de caso de uma rede de supermercados no Rio Grande do Sul. REDES, Santa Cruz do Sul, v. 16, n. 2, p. 227-252, mai./ago. 2011. 
MULHOLLAND, Caitlin. O princípio da relatividade dos efeitos contratuais. In: MORAES, Maria Celina Bodin de (Coord.). Princípios do direito civil contemporâneo. Rio de Janeiro: Renovar, 2006.

NEGREIROS, Teresa de paiva de Abreu Trigo de. Teoria do contrato: novos paradigmas. Rio de Janeiro: Renovar, 2006.

PENTEADO, Luciano de Camargo. Contratos eficazes perante terceiros. Revista do Advogado, São Paulo, ano 42, n. 116, jul. 2012.

PENTEADO, Luciano de Camargo. Efeitos contratuais perante terceiros. São Paulo: Quartier Latin do Brasil, 2007.

PENTEADO, Luciano de Camargo. Redes contratuais e contratos coligados. In: HIRONAKA, Giselda; TARTUCE, Flávio (Org.). Direito contratual: temas atuais. V. 1. São Paulo: Método, 2007.

PEREIRA, Caio Mario da Silva. Instituições de Direito Civil: contratos. V. III, 14 ed. Rio de Janeiro: Forense, 2010.

PEREIRA, Caio Mario da Silva. Instituições de Direito Civil: teoria geral das obrigações. V. II, 14 ed. Rio de Janeiro: Forense, 2010.

PINHEIRO, Rosalice Fidalgo; GLITZ, Frederico Eduardo Zenedin. A tutela externa do crédito e a função social do contrato: possibilidades do caso “Zeca Pagodinho". In: TEPEDINO, Gustavo; FACHIN, Luiz Edson (Coords.). Diálogos sobre Direito Civil. V. 2. Rio de Janeiro: Renovar, 2008.

POLACCO, V. Le obbligazioni nel diritto civile italiano. V. 1, 2 ed. Roma: Athenaeum, 1915.

POSNER, Eric. Análise econômica do direito contratual: sucesso ou fracasso? Tradução de Luciana Benetti Timm, Cristiano Carvalho e Alexandre Viola. São Paulo: Saraiva, 2010. 
QUARTA, Francesco. Risarcimento e sanzione nell'illecito civile. Napoli: Edizioni Scientifiche Italiane, 2013.

RESCIGNO, Pietro. L'abuso del diritto. Bologna: Il Mulino, 2001.

RODRIGUES JUNIOR, Otavio Luiz. A doutrina do terceiro cúmplice nas relações matrimoniais. In: TAVARES DA SILVA, Regina Beatriz; CAMARGO NETO, Theodureto de Almeida (Coords.). Grandes temas de direito de família e das sucessões. São Paulo: Saraiva, 2011.

RODRIGUES JUNIOR, Otavio Luiz. A doutrina do terceiro cúmplice: autonomia da vontade, o princípio res inter alios acta, função social do contrato e a interferência alheia na execução dos negócios jurídicos. Revista dos Tribunais, n. 821, p. 80-98, mar. 2004.

RODRIGUES, Silvio. Direito Civil: dos contratos e das declarações unilaterais de vontade. V. 3, 28 ed. São Paulo: Saraiva, 2007.

RODRIGUES, Silvio. Direito Civil: parte geral das obrigações. V. 2, 30 ed. São Paulo: Saraiva, 2007.

ROPPO, Enzo. O contrato. Tradução de Ana Coimbra e M. Januário C. Gomes. Coimbra: Almedina, 1988.

ROPPO, Vincenzo. Il Contratto. Milano: Giuffrè, 2001.

ROSENVALD, Nelson. In: PELUSO, Cezar (coord.). Código Civil comentado: doutrina e jurisprudência. 20 ed. Barueri: Manole, 2008.

ROTONDI, G. Dalla 'lex aquilia' all'art. 1.151 cod. civ. Ricerche storico-dogmatiche. Rivista del Diritto Commerciale, v. I, 1917. 
SALVESTRONI, Umberto. Ingiustificata lesion di interessi legittimi e danno ingiusto. Rivista Trimestrale di Diritto e Procedura Civile, Milano, v. 56, n. 1, mar. 2002.

SANTOS JÚNIOR, Eduardo. Da responsabilidade civil de terceiro por lesão do direito de crédito. Coimbra: Almedina, 2003.

SARASOLA, J. Madridejos. El perjuicio del credio por acto de tercero. In: Estudios de Derecho Privado. T. I. Madrid: Editorial Revista de Derecho Privado, 1962.

SAVATIER, René. La pretend principe de l'effet relative des contrats. Revue Trimestrielle de Droit Civil, Paris, t. 34, 1934.

SAYRE, Francis Bowers. Inducing breach of contract. Harvard Law Review, n. 36, p. 663$666,1922-1923$.

SCALISI, Vincenzo. Danno e ingiustizia nella teoria della responsabilità civile. Rivista Trimestrale di Diritto e Procedura Civile, Milano, v. 58, n. 3, sett. 2004.

SCALISI, Vincenzo. Ingiustizia del danno e analitica della responsabilità civile. Rivista di Diritto Civile, Milano, v. 50, n. 1, genn./feb. 2004.

TEDESCHI, Bianca Gardella. L'interferenza del terzo nei rapporti contrattuali: un'indaigne comparatistica. Milano: Giuffrè, 2008.

TEDESCHI, Guido. La tutela aquiliana del creditore contro i terzi com speciale riguardo al dirito inglese. RDC, Anno I, 1995.

TEPEDINO, Gustavo. Notas sobre a função social do contrato. In: Temas Controvertidos de Direito Civil. T. II. Rio de Janeiro: Renovar, 2009. 
TEPEDINO, Gustavo. Novos princípios contratuais e teoria da confiança: a exegese da cláusula to the best knowledge of the Sellers. T. 2. In: Temas de direito civil. Rio de Janeiro: Renovar, 2006.

THE AMERICAN LAW INSTITUTE. Case citations to the Restatement of the Law, Cumulative annual pocket part for use in 2013, reporting cases from july 2005 through june 2012. St. Paul: American Law Institute Publishers, 2013.

THE AMERICAN LAW INSTITUTE. Restatement of the law Second Torts. 2ed. v. 4. St. Paul: American Law Institute Publishers, 1979.

The English Reports. V. CXVIII, Kings Bench Division XLVII. London-Edinburgh: William Green \& Sons, Stevens \& Sons, 1911.

THEODORO JÚNIOR, Humberto. O contrato e sua função social. 3 ed. Rio de Janeiro: Forense, 2008.

THEODORO NETO, Humberto. Efeitos externos do contrato: direitos e obrigações na relação entre contratantes e terceiros. Rio de Janeiro: Forense, 2007.

TOMASEVICIUS FILHO, Eduardo. A função social do contrato: conceito e critérios de aplicação. In: CUNHA, Alexandre dos Santos (Coord.). O direito a empresa e das obrigações e o novo código civil brasileiro. São Paulo: Quartier Latin, 2006.

TRIMARCHI, Pietro. La responsabilitá del terzo per lezione del credito. In: ALPA, Guido; ZATTI, Paolo. Letture di diritto civile. Padova: Cedam, 1990.

VILLELA, João Baptista. Apontamentos sobre a cláusula “... ou devia saber”. Revista Brasileira de Estudos Políticos, v. 97, p. 179-200, 2008, p.181-182. Disponível em <http://www.pos.direito.ufmg.br/rbep/index.php/rbep/article/view/58/56>. Acesso em: 27 dez. 2017. 
VINEY, Geneviéve. Introdution à la responsabilité. In: GHESTIN, Jacques (Dir.). Traité de droit civil. 2 ed. Paris: L.G.D.J., 1995.

VISINTINI, Giovanna. Danno ingiusto e lesione di interessi legittimi. Contratto e Impresa, Padova, v. 17. n. 1, gen./apr. 2001.

VISINTINI, Giovanna. I Fatti Illeciti. Padova: Cedam, 1987.

VISINTINI, Giovanna. Tratatto breve della responsabilità civile: fatti illeciti. Inadempiemento. Danno risarcibile. Padova: Cedam, 2005.

WEBER, Ralph. Einige Gedanken zur Konkretisierung von Generalkaluseln durch Fallgrupen. Archiv für die Civilistische Praxis, v.192, 6º caderno. Tübingen: Mohr, 1992.

WEILL, Alex. La relativité des conventions en droit prive français. Paris: Dalloz, 1938.

WIEACKER, Franz. História do Direito Privado Moderno. 2 ed. Lisboa: Fundação Calouste. Gulbenkian, 1993.

WINTGEN, Robert. Étude critique de la notion d'opposabilité: les effets du contrat à l'égard des tiers en droit français et allemande. Paris, LGDJ, 2004.

ZANETTI, Cristiano de Sousa. Princípios. In: MORRIS, Amanda Zoe; BARROSO, Lucas Abreu (Coords.). Direito dos contratos. São Paulo: Revista dos Tribunais, 2008.

ZANETTI, Cristiano de Sousa. Responsabilidade pela ruptura das negociações. São Paulo: Juarez de Oliveira, 2005.

ZICCARDI, Fabio. L’induzione all'inadempiemento. Milano: Giuffrè, 1975. 
ZIMMERMAN, R. Roman law, contemporary law, European law: the civilian tradition today. Oxford: Oxford University Press, 2001. 